\title{
Quality in Teacher Education: A Reply to Alan Tom
}

Richard Wisniewski University of Oklahoma

Alan Tom's "An Alternative Set of NCATE Standards" is provocative. It makes a case for new standards that could dramatically reduce the confusion and compromises inevitable when a range of standards are applied. As one probes his ideas, however, they tend to simplify that which is obviously complex. As an advocate of NCATE, this writer is attracted to but not convinced by the arguments presented.

Dr. Tom puts foresquare the issue of quality in teacher education. It is an important statement deserving of discussion. One does not have to accept the four proposed standards as an alternate to the 27 current standards to applaud the theme of quality that pervades the article. It is precisely because of that theme that Professor Tom's ideas may not gain support. He raises uncomfortable questions and issues often ignored by the profession. He stresses the view that most teacher educators focus on the technical aspects of preparation rather than on the quality judgments that should characterize the process. His call for adequate financial support, selective admission standards, a vigorous faculty, and faculty involvement in schools would do much to resolve quality issues.

One can predict several reactions to the article. Some will see it as a simplistic attack on NCATE. How can the complicated process of teacher preparation be assessed by four standards? How can one dismiss the efforts and frustrations that have gone into creating the existing 27 standards? They were not designed by people avoiding quality issues. They were advanced by well-meaning individuals seeking ways to strengthen teacher education.

Professor Tom challenges the results of 25 years of work that led to the standards now in place. He may well be right that NCATE has too many standards. As Wheeler (1980) has correctly pointed out, too many NCATE reviews focus on the presence or absence of standards. If a standard can be shown to be present, the odds are overwhelming it will be met. The degree to which it is well met, the degree to which quality permeates its implementation, is an issue too easily glossed.

These comments should not be construed as suggesting that NCATE teams or the NCATE Council seek to avoid quality issues. It is far more likely that their actions reflect honest efforts to achieve quality. There is a tacit understanding, however, that this goal should be addressed without seriously challenging the teacher education establishment. This latter point is ignored by Professor Tom. His failure to comment on the politics of accreditation weakens his proposal, yet the political implications are clear. If quality were to be truly addressed, far more programs would be denied accreditation. Entire teacher education institutions might have to close their doors. Not many will raise standards if their professional self-interest is perceived as being threatened.

Wisniewski is Dean of Education at the University of OkJahoma, Norman, Oklahoma.
It has been a painstaking struggle to achieve the standards now in place. They are the result of conflicting interests and goals. It has also taken years to develop the cohesiveness and power NCATE is only beginning to exert. Indeed, one might suggest that some attacks on NCATE are motivated by the fact that NCATE is moving steadily toward addressing quality issues. There is much to lose for institutions and individuals in teacher education if NCATE becomes more than a paper tiger. Those deeply concerned with the quality of teacher education want NCATE to have teeth. Those who for a variety of reasons will not address quality issues struggle to prevent rigor in the application of standards.

If teacher education is to achieve full professional status, we must stop evading issues of quality. It is one thing to be cautious in our public pronouncements, but why do we so often speak of quality in hushed tones in our professional deliberations? The question is rhetorical, but Dr. Tom's comments are not. Indeed, they are refreshing. The debate over stronger admissions standards is but one illustration.

It has been a painstaking struggle to achieve the standards now in place. They are the result of conflicting interests and goals. It has also taken years to develop the cohesiveness and power NCATE is only beginning to exert.

Professor Tom is correct in stating that the quality of persons attracted to teacher education has shown a decline. It is a fact the public deserves to know. It is a fact those of us in teacher education must confront. It is not in the best interest of public education that it be staffed by persons lacking the intellectual and other qualities requisite to teaching. The responsibility for making admission judgments belongs to schools of education. It is not a buck we can continue to pass and expect to be respected or supported by the public. The fear that higher standards will reduce numbers and budgets is not a sufficient excuse. Budgets in and of themselves do not explain the norms and practices in schools of education. Building a profession means standing for quality. Despite some good signs, schools of education have not yet reached that stage.

Professor Tom implicitly criticizes the competency based movement, which often reduces teaching to particularistic behaviors. He criticizes teacher educators for their reluctance to apply rigorous admission standards with selective admission criteria. Yet it follows that rigorous standards of preparation and assessments of skills are outgrowths of selectivity - all of which are hallmarks of the competency movement. I would be pleased to read an elaboration in which Professor Tom makes suggestions about how to foster selectivity without fostering the competency movement.

Another reaction to $\mathrm{Dr}$. Tom will be that his ideas would 
emasculate NCATE. The argument will be that applying only four standards would reduce NCATE to such perfunctory reviews that some institutions will conclude that NCATE is not worth the effort. In contrast, some will point out that NCATE is already moving in directions proposed by Professor Tom. The NCATE Council recently approved a financial support statement for teacher education specifying a clinical ratio of 12 students to each professor as a desirable norm in funding programs. This new standard if implemented will meet the first requirement specified by Professor Tom. There is also growing support for quantifying other standards.

NCATE is a political organization, a con-
sortium of three groups: the teacher edu-
cation establishment, the National Educa-
tion Association, and a variety of specialty
groups.

Others may argue that Tom's standards make sense and should be additions to the 27 already in place. While Professor Tom would surely question such a proposal, this is perhaps the most likely reaction from those sympathetic to his views. The easiest solution is to add-on ideas rather than to re-examine all that has gone before. This approach would preserve standards of critical importance to segments of the profession. Persons recalling the struggle over the past decade to approve a multicultural standard, for example, will not give up this important gain. If one takes Professor Tom at face value, he would discard multiculturalism and the new special education standard, to cite another example. Supporters of these and other standards will either urge the addition of his standards or be forced to oppose them. He leaves no room for compromise.

His case would be stronger if he had argued that the proposed standards provide a prime focus. Other standards could be re-designed so as to elicit supportive information. For reasons not clear, he does not even note the political compromises inevitable in a full-scale reformation of standards.

Perhaps the major point ignored by Professor Tom is that NCATE is more than a set of standards. It is a political organization, a consortium of three groups: the teacher education establishment, the National Education Association, and a variety of specialty groups. The three groups involved represent the heart of the profession. The balance of power between them has been carefully cultivated and NCATE is far more unified and effective than in the past. If the NCATE governing groups could agree on the quality goals raised by Professor Tom, his ideas would have incredible power. Yet each group will react differently to the escalation of quality, and it is in the political process that hopes for tightening standards will be determined. While hardly an article of faith among teacher educators, any hope to strengthen teacher education is dependent on a strong partnership with teacher associations. There is no compelling reason to believe that teacher educators alone will increase the rigor of their programs. Were this possible, they would have done so decades ago. Teacher education is simply too fragmented to pull together on this or any other goal. The tension between large and small and public and private institutions is pervasive. Status, turf and fiscal considerations are constant spectres. If the process is to become more rigorous, teacher educators need strong allies. If these allies cannot be found in the teacher associations then the process is not worthy of preservation.

The governance of NCATE is paralleled by governance issues on campuses where teacher education often is weakly orchestrated. Professor Tom would do away with the governance standard when it is well known that programs on many campuses need the support of an accreditation body. He recognizes this fact, yet he would take from NCATE the teeth, dull as they may be, needed to address control over programs. It is not possible to press for quality without control over programs, and the governance standard is vital to that goal. One could easily attack Professor Tom by stating the rationale for still other standards. Such an attack is justified, for he has taken too simple a stand. If he had recognized that other standards are equally vital or should be given at least a secondary role, he would be more convincing. His position can only be weakened by the legitimate concerns of those who would preserve the existing standards.

Professor Tom's views are nonetheless compelling. Teacher education programs must become far more competitive for stronger students. Fears regarding fiscal support, the numbers game, and the other trappings of higher education simply beg the issue. Most teacher educators are aware of these issues and their consequences. But for the profession to continue to compromise on quality in both lean and fat times is simply a measure of its immaturity. Perhaps this says something about the quality of backbone on the part of many teacher educators. Whatever the causes, no profession deserves respect until it stands strongly for quality.

Perhaps the new NCATE finance standard will assist institutions in acquiring the fiscal support needed to operate first-rate clinically-based programs. Professional schools of education must be supported at the same level as comparable professional schools. Nothing less is acceptable. It is a national disgrace that teachers have been mass produced for generations. Neither the time nor the resources needed to prepare persons rigorously have been available other than in special cases. These second-rate practices must be halted. Public education will continue to decline if the quality of personnel issue is ignored. Teacher educators must be the prime advocates of professional levels of fiscal support so these trends can be halted.

Professor Tom's focus on faculty quality and scholarship is equally important and disconcerting. Nothing is more uncomfortable for professionals than to have to deal with questions about their own competence. Teacher educators do not differ on this score from persons in any other field. Each of us knows colleagues who are ineffective teachers, who are not well-trained, who are not current in their fields, who are not engaged in scholarship and who are divorced from the practicing profession. Yet they carry the same responsibilities as the strongest persons in the profession. Professor Tom's ideas will create much discomfort for such persons.

Others have raised similar questions. A group of deans recently circulated a document dealing with scholarship in schools of education; their experience confirms the sensitive nature of this issue (Tucker et al., 1981). Attacked as elit- 
ists and enemies of small colleges, they have uncovered a serious rift among teacher educators - a split that exists on every campus. Their policy inquiry argues that schools of education must be centers of inquiry on teaching, learning, and all other aspects of education. Not all schools can be knowledge producers, but all programs must be predicated on state-of-the-art research. Anything less than this condition reduces the status of schools of education and raises suspicion about the quality of their work. The link between scholarship and the quality of teaching and service is far too weak and must be addressed.

Dr. Tom's emphasis on strong working relationships with schools also is well taken. The debate on this issue revolves about the argument whether persons working in the field can aiso meet scholarly and other campus responsibilities. Given the strong tradition of campus-based teacher preparation, the answer must be affirmative. That answer must recognize that the expectations of some academic disciplines are not appropriate to professional schools. But whatever fine-tuning of expectations is needed, scholarship must not be ignored. The battle over professorial expectations rages on most campuses, and teacher education is not necessarily losing the struggle. The real issue is the denigration of scholarship in many schools of education. Too few teacher educators are active in scholarly pursuits. Yet the field and clinical practices of teacher education provide an incredibly rich mine for study. Teacher educators must become deeply involved in those activities, performing the dual role of clinicians and scholars. We have an opportunity to teach, study and practice in ways not as freely open to other professions. Indeed, the roles of teacher, scholar and clinician reinforce one another. They are all part of the same process, and the best among us demonstrate that fact daily. We need far more such persons in teacher education. With rare exceptions, we must all work with the field and be students of that process at the same time.

Other issues deserve discussion, but enough has been said to conclude that Professor Tom's article should not be dismissed. It is provocative and well documented.

My goal here has been to outline some likely reactions to and implications of his ideas. The critique is friendly, however. Professor Tom is to be congratulated for seeking to focus our attention on the only issue that truly counts: the quality of programs, students and faculty. It is an issue that has never been squarely faced by teacher educators. It must not be evaded any longer. Our integrity as a profession is dependent on how we respond.

\section{References}

Tucker, S., et al. Increasing the research capacity of schools of education: A policy inquiry. A report prepared for the N.I.E. Oregon State University, School of Education, March 1981.

Wheeler, C. NCATE: Does it matter? (Research Series No. 92). East Lansing, Michigan: Michigan State University, Institute for Research on Teaching, November 10, 1980.

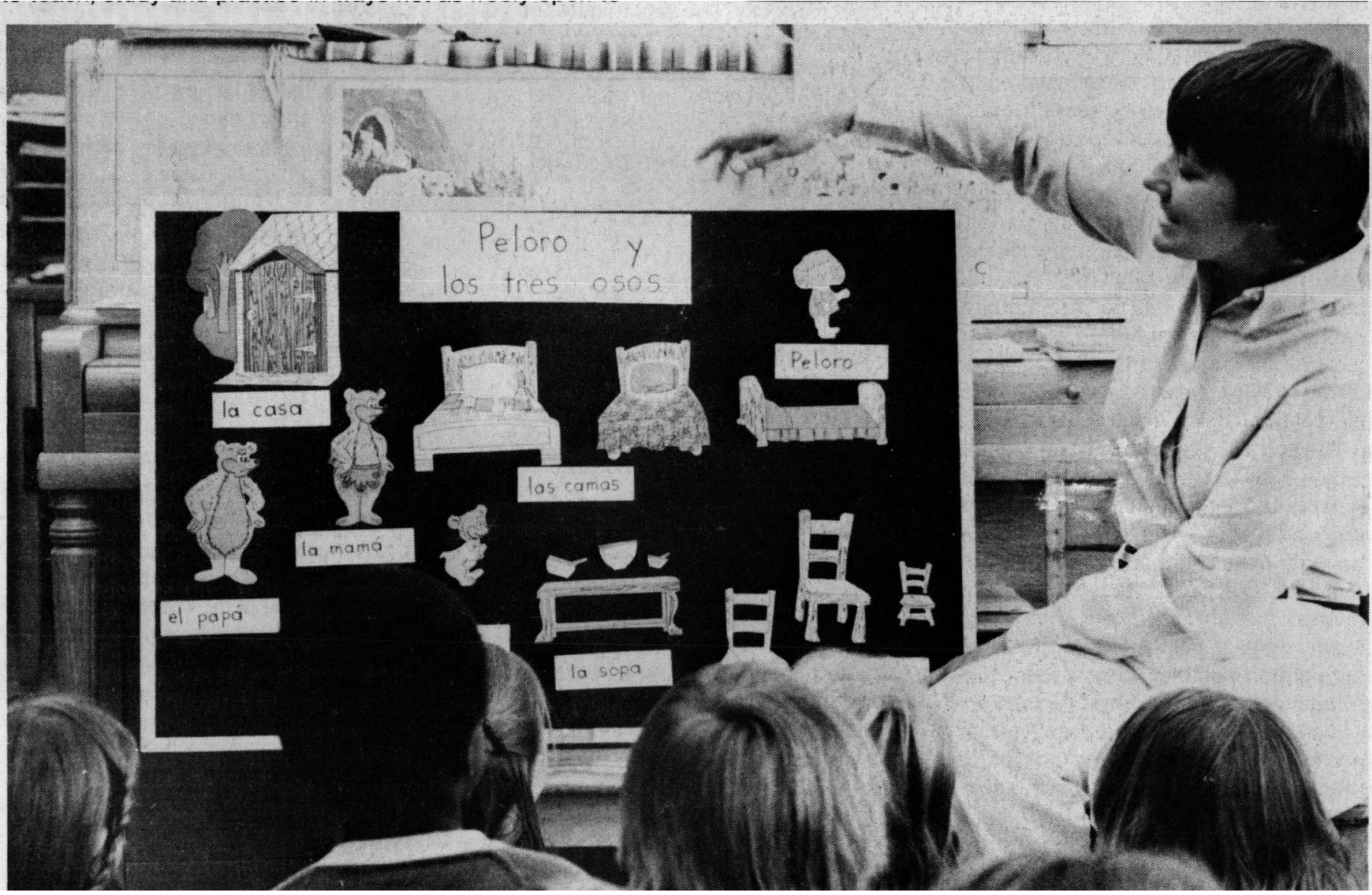

Photograph taken by the Media Department of the Milwaukee Public Schools at the Spanish Immersion Speciality School, Milwaukee, Wi. 